Check for updates

Cite this: RSC Adv., 2018, 8, 5608

\title{
D-Glucosamine production from chitosan hydrolyzation over a glucose-derived solid acid catalyst
}

\author{
Hongkui Zhang, ${ }^{a}$ Yuting Lu, ${ }^{a}$ Yuanhao Wang, (D) *a Xingrong Zhang*b \\ and Tingyu Wang ${ }^{c}$
}

A glucose-based solid acid catalyst (GSA) was synthesized by hydrothermal carbonization and its physicochemical properties were explored by various characterization techniques including IR, TG and SEM. In addition, its catalytic performance towards D-glucosamine formation from the hydrolysis of chitosan was extensively investigated to determine the effects of reaction parameters, such as reaction temperature, time and mass ratio of catalyst and reactants. The experimental results revealed that the yield of targeted product D-glucosamine could reach as high as $98.1 \%$ under optimal conditions (temperature: $110{ }^{\circ} \mathrm{C}$; time: $6 \mathrm{~h}$ ). After six catalytic cycles, no evident deactivation was observed, suggesting the satisfactory stability of the investigated solid acid catalyst. This might provide insight on the development of suitable catalyst systems for D-glucosamine formation to replace homogeneous catalysts.

Received 16th November 2017

Accepted 18th January 2018

DOI: $10.1039 / c 7 r a 12490 b$

rsc.li/rsc-advances

a combination of methods, such as the combination of acetic

\section{Introduction}

Chitosan is a partial deacetylation product of chitin which consists of $\beta$-(1-4)-2-amino-D-glucose and $\beta$-(1-4)-2-acetamido-Dglucose linked via 1,4- $\beta$-glucosidic bonds. It is the second most abundant biopolymer on earth coming from marine invertebrates, insects, fungi ${ }^{1}$ and bacteria etc.; obtained after treatment with $40 \%$ concentrated sodium hydroxide solution ${ }^{2}$ and produced on a scale of billions of tons annually. ${ }^{3}$ To date, chitosan has received more and more attention as a functional biopolymer for various applications from pharmaceuticals to commodity chemicals because of its non-toxicity, biodegradability, biocompatibility, ${ }^{4}$ non-antigenicity, antibacterial properties $^{5,6}$ and pilot-scale production. Its physicochemical properties greatly rely on the structure and the molecular weight. Therefore, chitosan generally presents special physiological properties, such as anti-tumor, anti-thrombotic and anticancer, if its molecular weight is reduced to a certain extent. ${ }^{7}$ Therefore, many methods including acid hydrolysis, ${ }^{\mathbf{8}, \mathbf{9}}$ formic acid, ${ }^{\mathbf{1 0}}$ nitrous acid hydrolysis, ${ }^{\mathbf{1 1}}$ phosphoric acid, ${ }^{\mathbf{1 2}}$ thermal degradation, ${ }^{13}$ oxidative-reductive degradation ${ }^{14}$ and enzymatic degradation ${ }^{15,16}$ have been developed to degrade chitosan. In order to achieve the promising degradable effect, ${ }^{17}$

${ }^{a}$ Faculty of Light Industry and Chemical Engineering, Dalian Polytechnic University, Dalian 116023, China.E-mail: yuanhaowang@126.com

${ }^{b}$ State Key Laboratory of Mineral Processing, Beijing General Research Institute of Mining and Metallurgy, Beijing 102600, China. E-mail: nichao6666@126.com

${ }^{c}$ College of Chemistry, Chemical Engineering and Materials Science, Soochow University, Suzhou 215006, China acid and sonication, ${ }^{18} \mathrm{H}_{2} \mathrm{O}_{2}$ and gamma irradiation, ${ }^{19} \mathrm{H}_{2} \mathrm{O}_{2}$ and microwave, ${ }^{20}$ acetic acid and microwave, ${ }^{21}$ mechanical-forceassisted with $\mathrm{H}_{2} \mathrm{SO}_{4}$ (ref. 22) and solid-state mechanochemical method ${ }^{23}$ have been employed. Ning Yan had investigated the degradation performance of acid to chitosan in different solvents, such as the system of aprotic polar solvents with water using an acid catalyst ${ }^{24}$ and ethylene glycol (EG) under the catalysis of sulfuric acid. ${ }^{25}$ After the degradation of chitosan by different hydrolysis methods, chitosan with low molecular weight, chitosan oligermers or D-glucosamine can be obtained, and they are widely used in food, medicine, cosmetics and material science fields.

Among these hydrolysis products, D-glucosamine is considered as one of the useful medicaments because of its biological, pharmaceutical and nutrimental effects. ${ }^{15}$ D-Glucosamine can also be used in wound healing, bone regeneration and as an antibacterial agent in dentistry. ${ }^{26}$ Apart from that, many materials in pharmaceutical, food and special materials processing industries ${ }^{27-29}$ might be synthesized from D-glucosamine, because it contains active amino groups. Based on these various applications, many hydrolysis methods, such as enzymatic degradation by Penicillium decumbens CFRNT15 (ref. 30) or cocktail, ${ }^{31}$ oxidative degradation in concentrated nitrous acid ${ }^{32}$ or hydrogen peroxide ${ }^{33}$ hydrolysis with concentrated $\mathrm{HCl}$ or $\mathrm{HCl}-\mathrm{H}_{3} \mathrm{PO}_{4}$ and acid hydrolysis in ionic liquids ${ }^{34}$ have been designed to produce D-glucosamine from chitosan. The degradation process of chitosan by expensive enzymes occurred under mild conditions, but possessed several drawbacks, such as the slow reaction rate, difficulty to handle, ${ }^{35-37}$ quick 
deactivation of the enzymes ${ }^{38}$ and the formation of other byproducts. ${ }^{32}$ At present, degradation of chitosan to synthesize D-glucosamine by a strong liquid acid, is the most common and effective method, but the degradation process normally requires excess acid loading, complex reactors and produce effluent disposal problems. ${ }^{39}$ In the presence of the excess acid, further degradation of D-glucosamine had taken place, leading to less yield. ${ }^{40,41}$

In addition to the above mentioned method, chitosan hydrolysis by a carbon-based solid acid may be a promising method to produce D-glucosamine. On the contrary to the homogeneous liquid acid, the heterogeneous solid acid catalyst could be easily separated from the reaction system, thereby reusable for the next catalytic cycle. Hence, hydrolysis of other polysaccharides by carbon-based solid acid catalyst had already been deeply investigated regarding its satisfactory performance. Ayumu Onda et $a l . .^{42}$ had reported the selective hydrolysis of cellulose into glucose using sulfonated active carbon. Nata et $a l .^{43}$ had prepared a highly sulfonated solid acid catalyst for the cornstarch hydrolysis. It had been demonstrated that the carbon-based solid acid catalyst can adsorb oligosaccharides as well as enzymes, resulting in the efficient catalytic hydrolysis. ${ }^{44,45}$ Daizo Yamaguchi ${ }^{44}$ had reported that an amorphous carbon material with $-\mathrm{SO}_{3} \mathrm{H},-\mathrm{COOH}$ and $-\mathrm{OH}$ groups present the high activity and selectivity for the hydrolysis of cellulose, and the functions of different groups had been discussed.

In the present study, a carbon-based solid acid catalyst bearing $-\mathrm{SO}_{3} \mathrm{H},-\mathrm{COOH}$ and $-\mathrm{OH}$ groups was synthesized by a hydrothermal method using renewable glucose as the precursor and used as an environment-friendly and recyclable catalyst for $\mathrm{D}$-glucosamine production from chitosan hydrolysis. The influences of experimental parameters were studied to identify the optimal reaction conditions. Additionally, several characterization techniques, such as IR, TG and SEM were carried out to determine the physicochemical features of the asprepared catalyst in order to establish the structure-activity relationship.

\section{Experimental}

\section{Materials}

D-Glucose, sulfuric acid, citric acid, acrylic acid, sodium hydroxide and other chemical regents were purchased from Sigma (St. Louis, USA) and used without further purification. Chitosan (800-2000 cP) with a DD value $45-97 \%$ was purchased from Sigma (St. Louis, USA), and used directly with no pretreatment.

\section{Catalyst preparation}

Glucose-derived solid acid catalyst was prepared by one-pot hydrothermal carbonization, as described in previous literature. ${ }^{36}$ Briefly, a mixture of glucose $(5.0 \mathrm{~g})$, citric acid $(2.5 \mathrm{~g})$, hydroxyethylsulfonic acid $(1.5 \mathrm{~g})$ and deionized water $(40.0 \mathrm{~mL})$ was placed in a Teflon-lined stainless steel autoclave $(100 \mathrm{~mL})$, and maintained at $180{ }^{\circ} \mathrm{C}$ for $4 \mathrm{~h}$. After cooling down to room temperature, the precipitate was thoroughly washed with hot deionized water and dried at $80^{\circ} \mathrm{C}$ for $8 \mathrm{~h}$ in a vacuum oven. The achieved catalyst is labelled as GSA in the following section.

The acid density $\left(\mathrm{mmol} \mathrm{g}^{-1}\right)$ of the investigated catalyst was determined by the neutralization titration method. ${ }^{46}$ Typically, catalyst $(0.2 \mathrm{~g})$ was added to an aqueous solution of $\mathrm{NaCl}$ $\left(0.1 \mathrm{~mol} \mathrm{~L}^{-1}, 20.0 \mathrm{~mL}\right)$. The mixture was sonicated for $1 \mathrm{~h}$ and then magnetically stirred for $24 \mathrm{~h}$ at room temperature. After centrifugal separation, the obtained filtrate $(5.0 \mathrm{~mL})$ was titrated with aqueous $\mathrm{NaOH}\left(0.05 \mathrm{~mol} \mathrm{~L}^{-1}\right)$ with phenolphthalein as the indicator.

\section{Catalyst characterization}

FT-IR spectra of the GSA catalyst were recorded and qualitatively analyzed using (FT/IR-430, JASCO, Japan). Samples were prepared by grinding into fine powders with $\mathrm{KBr}$. The spectrum was recorded in the range of $400-4000 \mathrm{~cm}^{-1}$.

Thermo-gravimetric analysis (TGA) measurement was conducted on a thermal analyzer TGA/SDTA 851 (Perkin-Elmer, USA). Samples $(20 \mathrm{mg})$ were placed in corundum crucibles non-hermetically closed with lids, and heated under argon from room temperature to $400{ }^{\circ} \mathrm{C}$ at a heating rate of $5{ }^{\circ} \mathrm{C} \mathrm{min}{ }^{-1}$.

Field emission scanning electron microscopy (FE-SEM) images of the samples were obtained by scanning electron microscope (JEOL, JSM-6500 LV).

$\mathrm{NH}_{3}$-TPD technique was used to estimate the acidity of the GSA catalyst. Prior to $\mathrm{NH}_{3}$ adsorption, the catalyst was outgassed at $300{ }^{\circ} \mathrm{C}$ for $1 \mathrm{~h}$. After cooling down to room temperature, $\mathrm{NH}_{3}$ adsorption was carried out under a flow of $\mathrm{NH}_{3} / \mathrm{He}$

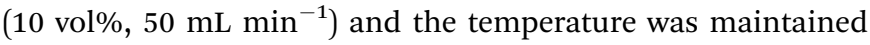
for $30 \mathrm{~min}$. Then, the flow was switched to $\mathrm{He}\left(50 \mathrm{~mL} \mathrm{~min}^{-1}\right)$ so as to remove the weakly adsorbed $\mathrm{NH}_{3}$. $\mathrm{NH}_{3}$-TPD was conducted in the He flow $\left(50 \mathrm{~mL} \mathrm{~min}^{-1}\right)$ by increasing the temperature to $800{ }^{\circ} \mathrm{C}$ with a heating rate of $5{ }^{\circ} \mathrm{C} \mathrm{min}^{-1}$, while the desorbed $\mathrm{NH}_{3}$ molecules were detected using online mass spectrometry (Inficon quadrupole).

\section{Hydrolysis of chitosan}

Performance of the catalyst was investigated by chitosan hydrolysis reaction as illustrated in Scheme 1. Chitosan was completely dissolved in a hydrochloric acid solution under magnetic stirring and then transferred to a Teflon-lined stainless steel autoclave, as well as the appropriate GSA sample. The role of hydrochloride was to protonate the amine groups of chitosan, avoiding the combination of amine groups with solid acid sites. After the reaction, the solution was cooled down to room temperature and was filtered. Formed D-glucosamine was quantitatively determined using HPLC (Watese2695) equipped with UV and refractive index (RI) detectors and a Shodex SUGAR SC1011 column $(8 \times 300 \mathrm{~mm})$. The column was operated at

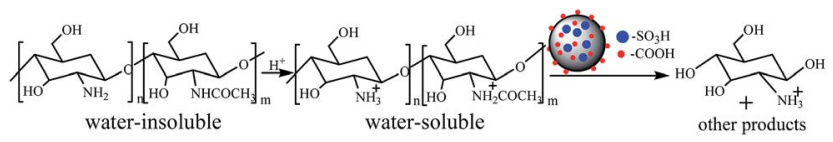

Scheme 1 The hydrolysis of chitosan over GSA catalyst. 
$70{ }^{\circ} \mathrm{C}$ and the operating temperature of detectors was set at $35{ }^{\circ} \mathrm{C}$. The mixture solution of NaOAc and HAc was used as the mobile phase at a flow rate of $0.6 \mathrm{~mL} \mathrm{~min}^{-1}$. The injection volume was $10 \mu \mathrm{L}$ of filtrate $(25 \mathrm{~mm})$. The yield of $\mathrm{D}$-glucosamine was calculated according to:

D-Glucosamine yield $(\%)=100 B[161 \mathrm{DD}+203(1-\mathrm{DD})] / m_{0}(1)$

where, $m_{0}$ refers to the amount of chitosan (g) and $B$ refers to the amount of D-glucosamine produced by acid-catalyzed hydrolysis (mol).

\section{Catalyst recyclability}

The recyclability of GSA catalyst for the hydrolysis of chitosan was investigated to estimate its catalytic stability. The reactions were repeated under identical experimental conditions as mentioned above. After each test, the aged catalyst was filtered, washed with hot deionized water and dried at $80{ }^{\circ} \mathrm{C}$ overnight for the next run.

\section{Results and discussion}

\section{Physicochemical properties of GSA catalyst}

The FT-IR spectrum of the solid acid is shown in Fig. 1(a). An obvious band due to the $\mathrm{O}-\mathrm{H}$ stretching mode of the $-\mathrm{COOH}$ groups was noticed at $3420 \mathrm{~cm}^{-1}$. The bands at $1614 \mathrm{~cm}^{-1}$ and $1385 \mathrm{~cm}^{-1}$ were assigned to aromatic-like $\mathrm{C}=\mathrm{C}$ stretching mode in polyaromatic compound. The band at $1709 \mathrm{~cm}^{-1}$ corresponds to the $\mathrm{C}=\mathrm{O}$ stretching mode of the $-\mathrm{COOH}$ group. ${ }^{47}$ The band at $1210 \mathrm{~cm}^{-1}$ was attributed to the sulfonate absorption of $\mathrm{C}_{4}-\mathrm{SO}_{3} \mathrm{H}^{43,48}$ The vibration bands at $1035 \mathrm{~cm}^{-1}$ $\left(-\mathrm{SO}_{2}-\right.$ symmetric stretching) evidenced the presence of $-\mathrm{SO}_{3} \mathrm{H}$ group. ${ }^{49}$

TGA curve of GSA sample is also presented in Fig. 1(b). The observed weight loss ( $\mathrm{ca} .5 \%$ ) below $100{ }^{\circ} \mathrm{C}$ is normally caused by the evaporation of adsorbed water on the catalyst surface. ${ }^{50} \mathrm{It}$ can be seen from Fig. 2(b) that only a $5 \%$ weight loss occurred
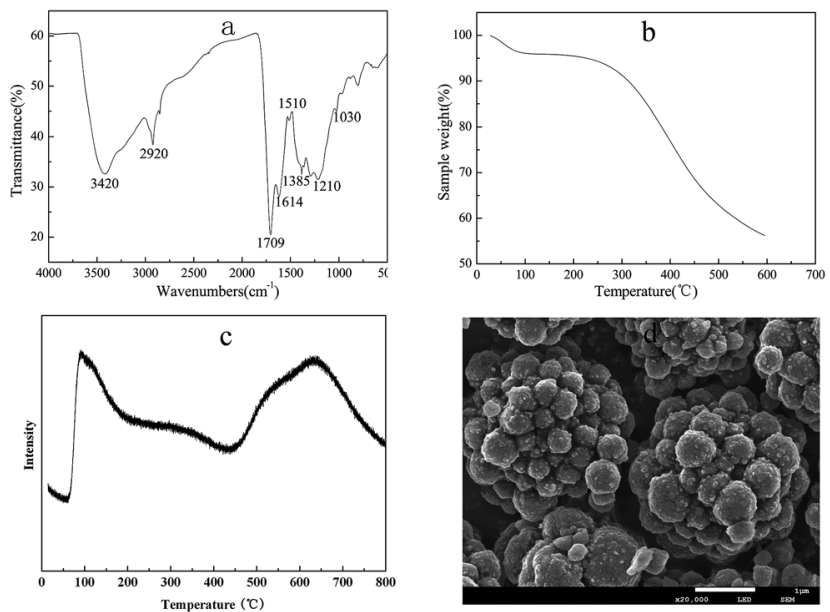

Fig. 1 FT-IR spectrum (a), TGA curve (b), $\mathrm{NH}_{3}-\mathrm{TPD}$ (c) and SEM images (d) of the as-prepared GSA catalyst.

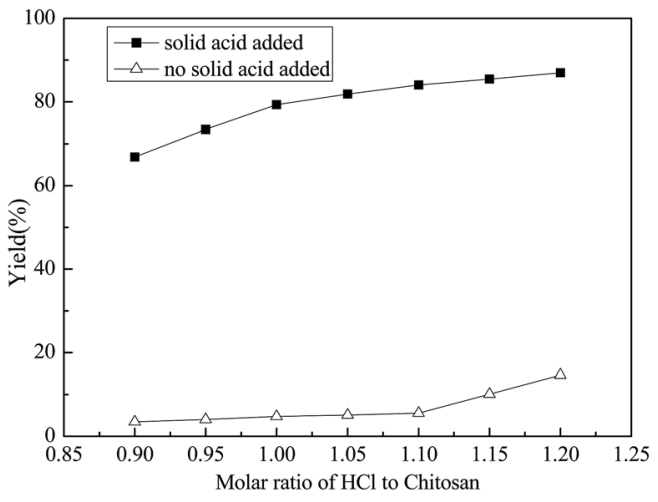

Fig. 2 Effect of the molar ratio of hydrochloric acid to chitosan on the yield of glucosamine (chitosan: $1.0 \mathrm{~g}$, mass of GSA: $0.2 \mathrm{~g}$, reaction time: $4 \mathrm{~h}$, reaction temperature: $100^{\circ} \mathrm{C}$ ).

with further increase in the temperature up to $250{ }^{\circ} \mathrm{C}$, suggesting a good thermal stability of the GSA catalyst. It could be effectively used below $250{ }^{\circ} \mathrm{C}$. In this work, reactions for the chitosan hydrolysis were conducted below $120{ }^{\circ} \mathrm{C}$. Therefore, the as-prepared GSA material was suitable for this reaction.

The acid density of the synthesized carbon-based solid acid was $1.9 \mathrm{mmol} \mathrm{g}^{-1}$, which was determined by the neutralization titration method. Fig. 1 (c) shows the $\mathrm{NH}_{3}$-TPD profile of solid acid catalysts. The peaks of $\mathrm{NH}_{3}$-desorption indicate the existence of acid sites with various strengths, and it was associated with the acidity strength. Normally, the higher desorption temperature corresponds to the stronger acid sites. The first peak, which was in the range of $100-200{ }^{\circ} \mathrm{C}$ maximized at $110{ }^{\circ} \mathrm{C}$, had been assigned for the hydrogen-bound ammonia (weak). ${ }^{49}$ The acid site on the GSA catalyst surface was denoted as a medium strong acid site, based on the peak at $340{ }^{\circ} \mathrm{C}$. The third peak at $650{ }^{\circ} \mathrm{C}$ corresponds to very strong acid sites. Considering the acid sites of the prepared GSA catalyst, the very strong acid sites were assigned to the $-\mathrm{SO}_{3} \mathrm{H}$ groups, ${ }^{50,51}$ whereas the weak and medium strong acid sites were assigned to the $-\mathrm{OH}$ groups and the $-\mathrm{COOH}$ groups on the catalyst surface.

As observed from SEM image (Fig. 1(d)), the solid acid particles produced by hydrothermal carbonization possessed spherical shapes with diameters in the range of $200-500 \mathrm{~nm}$. This result is consistent with the reports of Nata et $a l^{43}$ The presence of acrylic acid may promote glucose dehydration and polymerization, leading to more particle formation. Furthermore, acrylic acid might stabilize the newly formed carbonaceous particles and prevent their further aggregation in hydrothermal carbonization process, in order to obtain small particle sizes.

\section{Influence of hydrochloric acid concentration on the hydrolysis reaction}

Hydrochloric acid providing $\mathrm{H}^{+}$ions to protonate the amine groups of chitosan mainly possessed two merits. On one hand, chitosan could be completely dissolved in water if the amine groups were balanced by the adequate hydrogen ions. ${ }^{18}$ On the other hand, the sufficient protonation of the amine groups 
might avoid the neutralization reaction between the amine groups and the solid acid. However, excess hydrochloric acid may lead to the degradation of the targeted D-glucosamine.

Based on the above concern, the influence of the molar ratio of hydrochloric acid and chitosan on the hydrolysis reaction was studied and the results are shown in Fig. 2. When the ratio was less than 1.1, the yield of $\mathrm{D}$-glucosamine was less than $5.0 \%$. This might be because the $\mathrm{H}^{+}$ions provided by $\mathrm{HCl}$ mainly protonated the amine groups and the hydrolysis of chitosan was hindered. Moreover, the unprotonated amine groups of chitosan may have combined with acid sites in GSA sample, which might be partially related to the less catalytic behaviour. However, further increase of the amount of hydrochloric acid resulted in the increase of D-glucosamine yield. It was assumed that when an excess of $\mathrm{H}^{+}$ions are supplied by $\mathrm{HCl}$, the amount of solid acid consumed by the amino groups will be less. As a result, the yield of D-glucosamine increased gradually, with the same amount of solid acid. When the proportion of hydrochloric acid and chitosan exceeded 1.1, the amine groups were sufficiently protonated by an adequate number of hydrogen ions. The $\mathrm{H}^{+}$ions produced by $\mathrm{HCl}$ could lead to the hydrolysis of chitosan and eliminate the drawbacks that were mentioned in the introduction. Thus, 1.10 is the most appropriate molar ratio of hydrochloric acid to chitosan.

\section{Influence of time, temperature and catalyst mass on the yield of D-glucosamine}

The effect of hydrolysis time on the D-glucosamine yield was studied (chitosan: $1.0 \mathrm{~g}$, mass of GSA: $0.2 \mathrm{~g}$, reaction temperature: $\left.100{ }^{\circ} \mathrm{C}, n_{\mathrm{HCl}}: n_{\text {chitosan }}: 1.1\right)$ and the results are shown in Fig. 3. The yield of D-glucosamine increased from $68.7 \%$ to $91.2 \%$ with time up to $6 \mathrm{~h}$, and slightly decreased to $88.6 \%$ with further increase of time to $8 \mathrm{~h}$. It is generally accepted that a suitable extension of the reaction time is favourable for a solid acid to be in contact with the chitosan molecules and subsequently break the glycosidic bonds. However, further increase

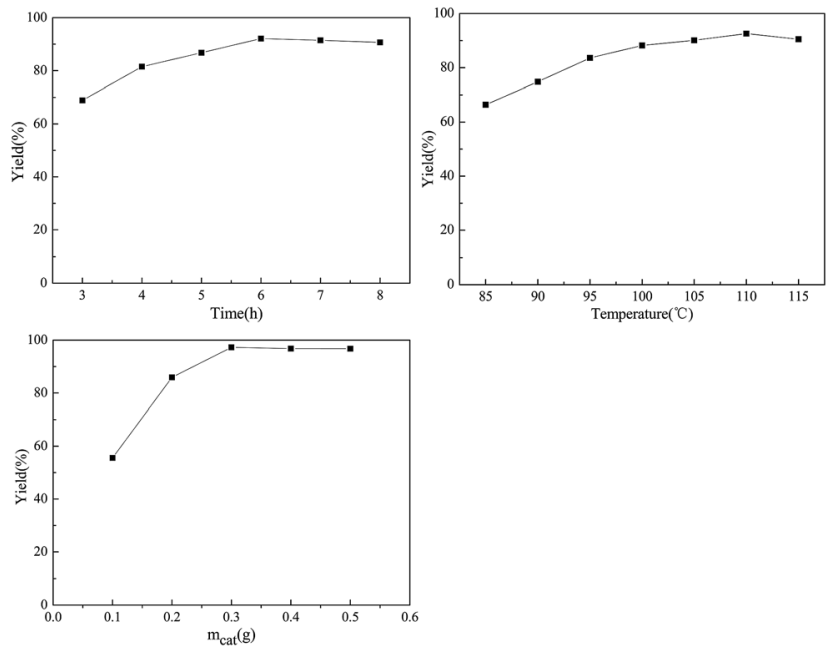

Fig. 3 Effect of time, temperature and catalyst mass $\left(m_{\text {cat }}\right)$ on the yield of $D$-glucosamine. of time may lead to further degradation of the targeted product $^{52}$ and form other undesirable species such as 5hydroxymethyl furfural. ${ }^{53}$

The reaction temperature effect on the hydrolysis of chitosan was also studied (chitosan: $1.0 \mathrm{~g}$, solid acid amount: $0.2 \mathrm{~g}$, reaction time: $\left.6.0 \mathrm{~h}, n_{\mathrm{HCl}}: n_{\text {chitosan: }}: 1.1\right)$. It was observed that the $\mathrm{D}$-glucosamine yield progressively increased with temperature and the maximum value $(92.3 \%)$ was achieved at $110^{\circ} \mathrm{C}$. A slight decline was observed upon heating to $115{ }^{\circ} \mathrm{C}$. It revealed that the reaction temperature greatly affects the yield of D-glucosamine. ${ }^{36}$ Based on the above results, the optimum reaction temperature might have to be maintained at $110^{\circ} \mathrm{C}$.

After probing the effects of reaction time and temperature, further studies were conducted to evaluate the role of the catalyst's mass (chitosan: $1.0 \mathrm{~g}$, reaction time: $6.0 \mathrm{~h}$, temperature: $110{ }^{\circ} \mathrm{C} n_{\mathrm{HCl}}: n_{\text {chitosan }}: 1.1$ ). The yield of D-glucosamine significantly increased with the increase of the catalyst's mass from 0.1 to $0.3 \mathrm{~g}$. When the weight of the catalyst was $0.3 \mathrm{~g}$, D-glucosamine yield could reach as high as $91.3 \%$ at $110^{\circ} \mathrm{C}$, after a $6 \mathrm{~h}$ reaction. With the addition of more sample, a slight decline of D-glucosamine yield took place. The hydrolysis of chitosan with the GSA catalyst is a heterogeneous system. It was assumed that the hydrogen bonds among - $\mathrm{OH}$ groups in the GSA catalyst caused the adsorption of oligosaccharides, and the $-\mathrm{SO}_{3} \mathrm{H}$ groups efficiently attacked the adsorbed oligosaccharides ${ }^{44}$ If the amount of the GSA catalyst is less, the few number of hydroxyl groups can not completely adsorb the chitosan molecules on the surface of the catalyst. Consequently, the $-\mathrm{SO}_{3} \mathrm{H}$ or the $-\mathrm{COOH}$ groups can not efficiently attack the $1,4-\beta$-glucosidic bonds of chitosan. Thus, the optimum amount of solid acid was set at $0.3 \mathrm{~g}$.

\section{Effect of DD of chitosan on D-glucosamine production}

Chitosan is a partially deacetylated product of chitin, and the Dglucosamine unit rely on the degree of deacetylation (DD). The yield of D-glucosamine with different DD of chitosan was investigated and the results are shown in Fig. 4. It was apparent that the D-glucosamine yield was closely related with the DD of chitosan. Under optimal reaction conditions, the yield of $\mathrm{D}^{-}$ glucosamine increased from $40.0 \%$ to $98.1 \%$ with the increase

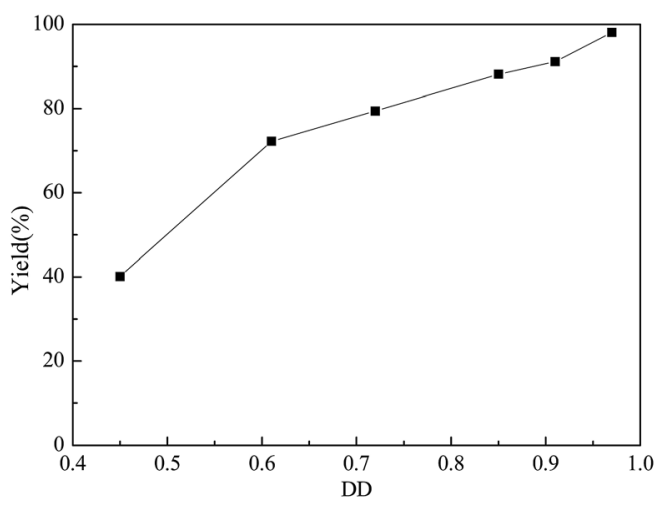

Fig. 4 Effect of DD on the yield of D-glucosamine (chitosan: $1.0 \mathrm{~g}$, solid acid: $0.3 \mathrm{~g}$, reaction time: $6.0 \mathrm{~h}$, reaction temperature: $110{ }^{\circ} \mathrm{C}$, $\left.n_{\mathrm{HCl}}: n_{\text {chitosan }}: 1.1\right)$. 


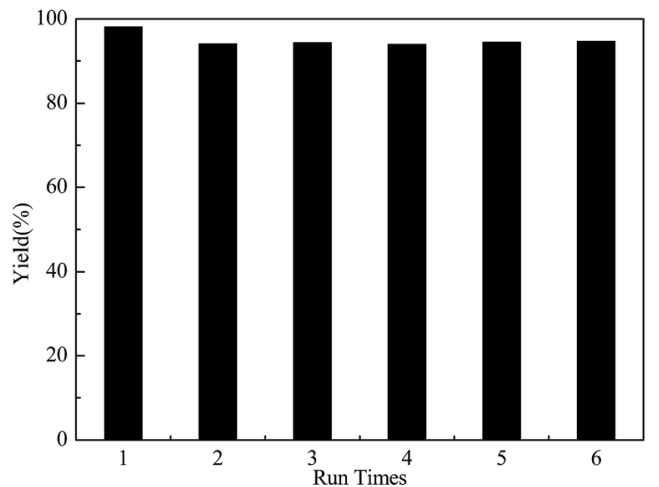

Fig. 5 Recyclability of the GSA sample (chitosan: $1.0 \mathrm{~g}$, mass of GSA: $0.3 \mathrm{~g}$, reaction time: $6.0 \mathrm{~h}$, reaction temperature: $110^{\circ} \mathrm{C}, n_{\mathrm{HCl}}$ : chitosan: 1.1).

of the DD of chitosan from 0.45 to 0.97 . The result indicates that the GSA catalyst can cause the fracture of the chitosan, but the deacetylation of the chitosan is very weak.

Besides, the D-glucosamine yield with DD of 0.45 was only $c a$. $40 \%$, which was much less than the theoretical concentration of D-glucosamine. The extent of the crystallinity of chitosan was inversely associated with its DD. ${ }^{54}$ It was concluded that the chitosan chains with low DD could result in a more compact structure that might enhance the radical-radical combinations of the chains. ${ }^{55}$ In addition, acetyl groups in the chitosan chains with low DD can aggregate in solution, because of their hydrophobic interactions. ${ }^{56}$ This might have prevented the contact between the solid acid catalyst and chitosan molecules, which led to the unsatisfactory catalytic performance.

\section{Recyclability of the GSA catalyst}

Recyclability is considered as one of the important characteristics of a promising solid acid catalyst, to reduce the cost. Hence, the stability of the catalyst was investigated. As shown in Fig. 5, the yield of D-glucosamine maintained a constant value, even after the catalyst was repeatedly being used for 6 times. It can be concluded that the GSA catalyst could easily be reused without any remarkable deactivation.

\section{Conclusions}

Spherical, glucose-derived solid acid (GSA) catalyst bearing $-\mathrm{SO}_{3} \mathrm{H},-\mathrm{OH}$ and $-\mathrm{COOH}$ groups, was demonstrated to be an efficient catalyst system for the hydrolysis of chitosan to produce D-glucosamine. A maximum yield of D-glucosamine (98.1\%) could be achieved. The GSA sample was easily synthesized, and no obvious deactivation was observed even after six consecutive runs. This might open a relatively green route for chitosan hydrolysis over heterogeneous catalysts, instead of conventional liquid acid catalysts.

\section{Conflicts of interest}

We declare that we have no financial and personal relationships with other people or organizations that can inappropriately influence our work, there is no professional or other personal interest of any nature or kind in any product, service and/or company that could be construed as influencing the position presented in, or the review of, the manuscript entitled, "A method of hydrolyzing chitosan to produce D-glucosamine by carbon-based solid acid".

\section{Acknowledgements}

This work was supported by the Scientific Research Fund of Liaoning Provincial Education Department (grant number L2014223); and the Youth Foundation of Dalian Polytechnic University (grant number QNJJ201303).

\section{References}

1 X. Chen, H. Yang and N. Yan, Chem.-Eur. J., 2016, 22, 1340213421.

2 N. Yan and X. Chen, Nature, 2015, 13, 155-157.

3 M. R. Kasaai, J. Agric. Food Chem., 2009, 57, 1667-1676.

4 R. L. Carmen and B. Roland, J. Controlled Release, 1997, 44, 215-225.

5 J. Rhoades, G. Gibson, K. Formentin, M. Beer and R. Rastall, Carbohydr. Polym., 2006, 64, 57-59.

6 A. Sawaguchi, S. Ono, M. Oomura, K. Inami, Y. Kumeta, K. Honda, R. Sameshima-Saito, K. Sakamoto, A. Ando and A. Saito, Soil Sci. Plant Nutr., 2015, 61, 471-480.

7 S. Yu, P. Chen, X. Liu and L. Li, Catal. Lett., 2015, 145, 18451850.

8 B. Li, J. Zhang, F. Bu and W. Xia, Carbohydr. Res., 2013, 366, 50-54.

9 X. Yan and H. M. Evenocheck, Carbohydr. Polym., 2012, 87, 1774-1778.

10 J. Zhang and N. Yan, Green Chem., 2016, 18, 5050-5058.

11 Z. Han, Y. Zeng, H. Lu and L. Zhang, Carbohydr. Res., 2015, 413, 75-84.

12 L. A. Nudga, V. A. Petrova, E. E. Kever and T. V. Makarova, Russ. J. Appl. Chem., 2002, 75, 1864-1867.

13 V. Georgieva, D. Zvezdova and L. Vlaev, Chem. Cent. J., 2012, 6, 81-90.

14 Z. Ma, Y. Wu, Y. He and T. Wu, RSC Adv., 2013, 3, 1204912051.

15 Y. Sun, J. Zhang, S. Wu and S. Wang, Int. J. Biol. Macromol., 2013, 61, 160-163.

16 Q. Lu, Y. Shi, S. Wang, Y. Yang, B. Han, W. Liu, D. N. M. Jones and W. Liu, Biochim. Biophys. Acta, 2015, 18(50), 1953-1961.

17 Q. Chen, W. Xiao, L. Zhou, T. Wu and Y. Wu, Polym. Degrad. Stab., 2012, 97, 49-53.

18 E. Savitri, S. R. Juliastuti, A. H. Sumarno and A. Roesyadi, Polym. Degrad. Stab., 2014, 110, 344-352.

19 M. Mahmud, M. I. Naziri, N. Yacob, N. Talip and Z. Abdullah, Am. Inst. Phys., 2014, 19, 136-140.

20 K. Li, R. Xing, S. Liu, Y. Qin, X. Meng and P. Li, Int. J. Biol. Macromol., 2012, 51, 767-773.

21 J. M. Wasikiewicz and S. G. Yeates, Polym. Degrad. Stab., 2013, 98, 863-867. 
22 M. Yabushita, H. Kobayashi, K. Kuroki, S. Ito and A. Fukuoka, ChemSusChem, 2015, 8, 3760-3763.

23 X. Chen, H. Yang, Z. Zhong and N. Yan, Green Chem., 2017, 19, 2783-2792.

24 J. Zhang and N. Yan, ChemCatChem, 2017, 9, 2790-2796.

25 Y. Pierson, X. Chen, F. D. Bobbink, J. Zhang and N. Yan, ACS Sustainable Chem. Eng., 2014, 2, 2081-2089.

26 S. G. Kirkham and K. Samarasinghe, J. Orthop. Surg., 2009, 17, 72-76.

27 T. Sun, D. Zhou, J. Xie and M. Fang, Eur. Food Res. Technol., 2007, 225, 451-456.

28 M. Yang, H. Shen, Y. Li, C. Shen and P. Zhang, RSC Adv., 2014, 4, 286-295.

29 L. Jia, Y. Wang, Y. Qiao, Y. Qi and X. Hou, RSC Adv., 2014, 4(44), 253-260.

30 T. Nidheesh, P. Gaurav Kumar and P. V. Suresh, Int. Biodeterior. Biodegrad., 2015, 97, 97-106.

31 S. Mekasha, H. Toupalová, E. Linggadjaja, H. A. Tolani, L. Anděra, M. Ø. Arntzen, G. Vaaje-Kolstad, V. G. H. Eijsink and J. W. Agger, Carbohydr. Res., 2016, 433, 18-24.

32 G. A. M. Peyron, Carbohydr. Res., 1995, 277, 257-272.

33 K. L. Chang, M. C. Tai and F. H. Cheng, J. Agric. Food Chem., 2001, 49, 4845-4851.

34 Z. Zhang, C. Li, Q. Wang and Z. K. Zhao, Carbohydr. Polym., 2009, 78, 685-689.

35 M. Mei, K. Takashi, I. Sosaku and M. Sukekuni, Food Sci. Technol. Res., 2006, 12, 85-90.

36 K. M. Anna, V. M. F. Lai, F. Fiedorowicz, K. Gohar and T. Piotr, Biotechnol. Prog., 2008, 24, 385-388.

37 M. Ming, T. Kuroiwa, S. Ichikawa, S. Sato and S. Mukataka, Biochem. Eng. J., 2006, 28, 289-294.

38 A. Konieczna-Molenda, M. Fiedorowicz, W. Zhong and P. Tomasik, Carbohydr. Res., 2008, 343, 3117-3119.

39 K. M. V. Aslak Einbu, Biomacromolecules, 2008, 9, 1870-1875.

40 A. Einbu, H. Grasdalen and K. M. Vårum, Carbohydr. Res., 2007, 342, 1055-1062.
41 K. M. Varum and O. Smidsrod, Carbohydr. Polym., 2001, 46, 89-98.

42 A. Onda, T. Ochi and K. Yanagisawa, Green Chem., 2008, 10, 1033-1039.

43 I. F. Nata, C. Irawan, P. Mardina and C.-K. Lee, J. Solid State Chem., 2015, 230, 163-168.

44 S. Satoshi, N. Kiyotaka, K. Masaaki, Y. Daizo, K. Hideki, H. Shigenobu and H. Michikazu, J. Am. Chem. Soc., 2008, 130, 12787-12793.

45 D. Yamaguchi and M. Hara, Solid State Sci., 2010, 12, 10181023.

46 R. S. Thombal, A. R. Jadhav and V. H. Jadhav, RSC Adv., 2015, 5, 12981-12986.

47 G. Chen and B. Fang, Bioresour. Technol., 2011, 102, 26352640.

48 R. A. Krishnan, P. Deshmukh, S. Agarwal, P. Purohit, D. Dhoble, P. Waske, D. Khandekar, R. Jain and P. Dandekar, Carbohydr. Polym., 2016, 151, 417-425.

49 J. Zou, D. Cao, W. Tao, S. Zhang, L. Cui, F. Zeng and J. Cai, RSC Adv., 2016, 6, 49528-49536.

50 M. L. Ibrahim, R. Umer and H. T. Y. Yun, Arabian J. Chem., 2016, 9, 178-189.

51 I. M. Lokman, M. Goto, U. Rashid and Y. H. Taufiq-Yap, Chem. Eng. J., 2016, 284, 872-878.

52 M. H. Zong, Z. Q. Duan, W. Y. Lou, T. J. Smith and H. Wu, Green Chem., 2007, 9, 434.

53 H. Liu, J. Bao, Y. Du, X. Zhou and J. F. Kennedy, Carbohydr. Polym., 2006, 64, 553-559.

54 M. Dash, F. Chiellini, R. M. Ottenbrite and E. Chiellini, Prog. Polym. Sci., 2011, 36, 981-1014.

55 T. Pinar, C. Hazal and M. Sen, Radiat. Phys. Chem., 2014, 94, 236-239.

56 Y. Wang, B. Ju and S. Zhang, Carbohydr. Polym., 2012, 90, 696-702. 